\title{
Glucose metabolism-related gene polymorphisms as the risk predictors of type 2 diabetes
}

\author{
Cuilin $\mathrm{Li}^{1 *} \mathbb{D}$, Yuping Yang ${ }^{1}$, Xin Liu ${ }^{1}$, Zhongyu Li ${ }^{2}$, Hong Liu ${ }^{3}$ and Qiuhong Tan ${ }^{1}$
}

\begin{abstract}
Type 2 diabetes mellitus (T2DM) is a complex polygenic metabolic disease characterized by elevated blood glucose. Multiple environmental and genetic factors can increase the risk of T2DM and its complications, and genetic polymorphisms are no exception. This review is mainly focused on the related genes involved in glucose metabolic, including G6PC2, GCK, GCKR and OCT3. In this review, we have summarized the results reported globally and found that the genetic variants of GCK and OCT3 genes is a risk factor for T2DM while G6PC2 and GCKR genes are controversial in different ethnic groups. Hopefully, this summary could possibly help researchers and physicians understand the mechanism of T2DM so as to diagnose and even prevent T2DM at early time.
\end{abstract}

Keywords: Type 2 diabetes mellitus, Genetic polymorphism, G6PC2, GCK, GCKR, OCT3

\section{Background}

Diabetes is one of the major chronic disease threatening human health. There were 451 million people with diabetes worldwide up to 2017. And it was estimated that in 2045 the number of diabetes patients will increase to 693 million [1]. In China, the estimated numbers of Type 2 Diabetes Mellitus (T2DM) was 113.9 million, representing $11.6 \%$ of Chinese population [2]. T2DM is a lifelong disease characterized by hyperglycemia, showing with drinking more, eating more, peeing more and losing weight. If the glucose is not efficiently controlled, the patients will have more chance to develop complications, such as nephropathy, peripheral neuropathy, diabetic retinopathy, amputation, vascular disease, heart disease and stroke. These complications ultimately decrease the quality of life, increase the economic burden of patients [3]. T2DM can be caused by various factors, including obesity, physical inactivity, family history, hypertension

*Correspondence: licuilincindy@163.com

${ }^{1}$ Department of Pharmacy, The Affiliated Zhuzhou Hospital Xiangya Medical College CSU, Zhuzhou 412007, Hunan, China

Full list of author information is available at the end of the article and age [4]. Apart from these, genetic factors are considerable since many genes and their interactions play important roles in the development of T2DM [5], such as PRKAA2 [6], ABCA1 [7], FTO [8], FADS [9] and TCF7L2 [10]. Therefore, finding and summarizing the gene variants among different ethnic groups will be helpful to understand the treatment, prevention and complications of T2DM.

\section{Candidate genes for T2DM}

People with family history of diabetes will have 2-4 times higher risk to develop T2DM than the unrelated individuals [11]. With the development of pharmacogenomics, more and more genetic variants were reported to associated with the susceptibility and treatment of T2DM. As we all know, single nucleotide polymorphism (SNP) is one of the main forms of genetic variation, which can affect the expression of glucose metabolism-related gene. Glucose metabolism-related gene is involved in glucose regulation (Fig. 1), thus affecting the susceptibility of T2DM. In this review, we will focus on G6PC2, $G C K, G C K R$, and OCT3 genes and their association with the susceptibility of T2DM as shown in Table 1 . 


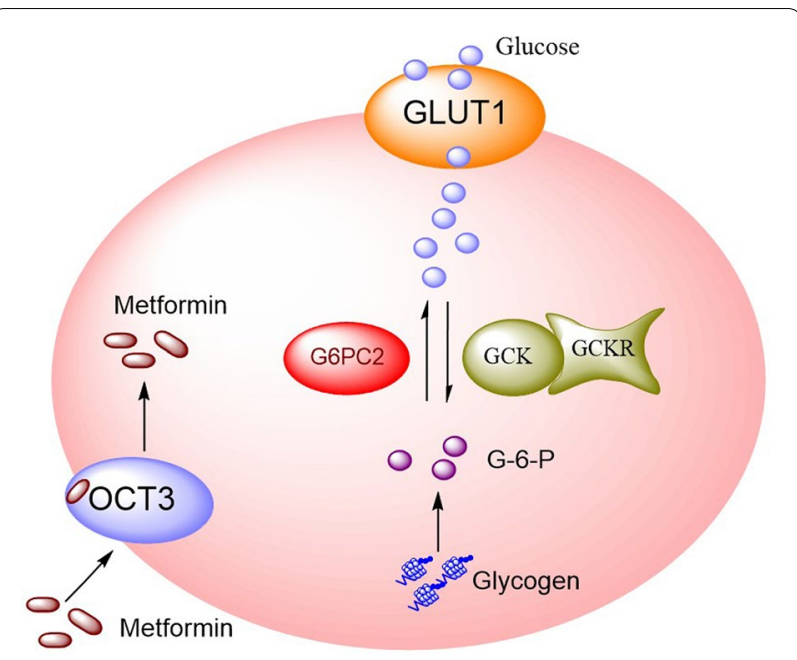

Fig. 1 Glucose metabolism-related gene involving in glucose regulation. Glucose is taken up into the hepatic cell via glucose transporters 1 (GLUT1). In the process of glycogenolysis, liver glycogen is hydrolyzed and isomerized to glucose-6-phosphatase (G-6-P). Then glucose-6-phospatase catalytic subunit 2 (G6PC2) catalyzes the production of free glucose to maintain blood glucose balance, and this process is also the key step of gluconeogenesis. In the process of glucose activation, glucokinase (GCK) and glucokinase regulator (GCKR) is the key enzyme to regulate glucose phosphorylation, which followed by glycolysis and aerobic oxidation. At the same time, organic cation transporter 3 (OCT3) is a transporter of metformin, which involved in the regulation of $\mathrm{HbA1c}$ levels and glucose

The products of these genes are related to the biochemical pathway leading to T2DM or higher blood glucose. The enzyme encoded by G6PC2 belong to the glucose6-phosphatase catalytic subunit family, which is involved in the terminal step in gluconeogenic and glycogenolytic pathways, allowing the release of glucose into the bloodstream. The product of $G C K$ is responsible for regulating glucose and the secretion of insulin. Products of GCKR inhibits glucokinase in liver and pancreatic islet cells by binding non-covalently to form an inactive complex with the enzyme. OCT3, also named $S L C 22 A 3$, is critical for elimination and transportation of many endogenous small organic cations as well as a wide array of drugs and environmental toxins.

\section{Glucose-6-phosphatase catalytic subunit 2 (G6PC2) gene}

G6PC2 is part of the glucose-6-phosphatase catalytic subunit family, which can catalyze the hydrolysis of glucose-6-phosphate, allowing the release of glucose into the bloodstream. G6PC2 is located at $2 \mathrm{q} 31.1$ on human chromosome with 4 exons. This gene encodes a 355 amino acid protein which is a negative regulator of basal glucose-stimulated insulin secretion. The deletion of G6PC2 in pancreatic islet beta cell was reported to reduce fasting blood glucose [24]. GWAS and mouse studies suggested that single nucleotide polymorphisms in $G 6 P C 2$ gene were associated with variations in fasting blood glucose (FBG) but not fasting plasma insulin [25]. A research in Science reported that SNP rs560887 in $G 6 P C 2$ gene was associated with FBG and pancreatic beta cell function but not associated with T2DM risk in three populations [26]. A study on Europeans shown that G6PC2 rs560887, rs2232316 and rs13431652 were potentially causative SNPs of elevated FBG level [27]. A low-frequency and rare exome chip found that G6PC2 rs138726309 (H177Y), rs2232323 (Y207S), rs146779637 (R283X) and rs2232326 (S324P) were associated with FG [28]. Further, various studies suggested that the polymorphisms and haplotypes in G6PC2 gene were associated with susceptibility of T2DM [29]. In Chinese population, $\mathrm{Li}$ et al. verified that the $\mathrm{C}$ allele of rs780094 and the GC genotype of rs492594 were significantly associated with the increased risk of T2DM. Also, this research found G6PC2 and GCKR haplotypes were associated with the susceptibility of T2DM [12]. Apart from this, another research also demonstrated the relationship between rs492594 and T2DM risk. G6PC2 rs16856187 was shown as the strongest evidence for the association with T2DM [13]. However, the results seem controversial in Chinese population. While another study found no significant association between rs16856187 and T2DM risk [12]. Maybe this discrepancy is the results of the interaction of gene-region or gene-environments. After all, China is a vast country with huge variation on geography. Rs2232328 and rs492594 were also reported to influence the susceptibility of T2DM in Arabian [14].

\section{Glucokinase (GCK) gene}

Glucokinase $(G C K)$ can catalyze the phosphorylation of glucose to glucose-6-phosphate. In pancreatic $\beta$-cell, it plays a significant role in regulating glucose metabolism and insulin secretion [30]. Therefore, it is understandable that the mutation or polymorphism of GCK gene can cause pathoglycemia and diabetes mellitus. It is reported that mutation of GCK is associated with Chinese MODY (maturity onset diabetes of young type) [31]. The meta-analysis shown that the polymorphisms of GCK rs1799831 was associated with gestational diabetes mellitus (GDM) in Indian population [32]. Genetic polymorphism in GCK gene has been shown to be associated with the susceptibility of T2DM. 3'UTR SNP, chr7:44,184,184G/A in GCK was reported to influences the rate of oxidation of carbohydrate, $24 \mathrm{~h}$ energy expenditure and diabetes risk in Pima Indians. Compared with individuals with $A$ allele, individuals with $\mathrm{G}$ allele had lower rate of oxidation of lipid and higher $24 \mathrm{~h}$ energy expenditure 
Table 1 Summarize of G6PC2, GCK, GCKR, and OCT3 gene polymorphism with T2DM in various ethnic groups

\begin{tabular}{|c|c|c|c|c|c|c|}
\hline Gene & Polymorphism & Significance & OR & Case/Control & Ethnicity & References \\
\hline \multirow[t]{9}{*}{ G6PC2 } & $\begin{array}{l}\text { rs } 492594 \\
G>C\end{array}$ & Y & 0.57 & $538 / 538$ & Han Chinese & [12] \\
\hline & $\begin{array}{l}r s 492594 \\
G>C\end{array}$ & Y & 1.14 & $1876 / 1800$ & Eastern Han Chinese & [13] \\
\hline & $\begin{array}{l}\mathrm{rs} 492594 \\
\mathrm{G}>\mathrm{C}\end{array}$ & Y & 1.70 & $185 / 377$ & RIYADH COHORT & [14] \\
\hline & rs13387347T >C & Y & 1.17 & $1876 / 1800$ & Eastern Han Chinese & [13] \\
\hline & $\mathrm{rs} 13387347 \mathrm{~T}>\mathrm{C}$ & $N$ & & $538 / 538$ & Han Chinese & [12] \\
\hline & rs16856187 A >C & Y & 1.19 & $1876 / 1800$ & Eastern Han Chinese & [13] \\
\hline & rs16856187 A >C & $N$ & & $538 / 538$ & Han Chinese & [12] \\
\hline & rs2232316 G > A & $\mathrm{N}$ & & $1876 / 1800$ & Eastern Han Chinese & [13] \\
\hline & rs 2232328 C > G & Y & 1.64 & $185 / 377$ & RIYADH COHORT & [14] \\
\hline \multirow[t]{6}{*}{ GCK } & rs4607517T>C & Y & 1.20 & $853 / 3210$ & American Indians & [15] \\
\hline & rs1476891 A>G & Y & 1.26 & $1658 / 1946$ & Pima Indians & [15] \\
\hline & rs55714218 G>- & Y & 0.84 & $853 / 3210$ & American Indians & [15] \\
\hline & rs1799884 G>A & Y & 1.12 & $2628 / 2041$ & Netherlands & [16] \\
\hline & rs1799884 G > A & Y & 1.23 & $1244 / 3189$ & French & [17] \\
\hline & rs1799884 G > A & Y & 1.24 & $1193 / 1055$ & Moroccans & [18] \\
\hline \multirow[t]{9}{*}{ GCKR } & $\begin{array}{l}\text { rs780094 } \\
G>A\end{array}$ & Y & 1.78 & $538 / 538$ & Han Chinese & [12] \\
\hline & $\begin{array}{l}\text { rs780094 } \\
G>A\end{array}$ & Y & 0.67 & $424 / 1884$ & Han Chinese & [19] \\
\hline & $\begin{array}{l}\text { rs780094 } \\
G>A\end{array}$ & $N$ & & $736 / 768$ & Northern Han Chinese & [20] \\
\hline & $\begin{array}{l}r s 780094 \\
G>A\end{array}$ & Y & 0.71 & $488 / 398$ & Japanese & [21] \\
\hline & $\begin{array}{l}\text { rs780094 } \\
\text { G>A }\end{array}$ & Y & 1.22 & $1118 / 1161$ & Han Chinese & [22] \\
\hline & $\begin{array}{l}\mathrm{rs} 1260326 \\
\mathrm{C}>\mathrm{T}\end{array}$ & Y & 0.74 & $424 / 1884$ & Han Chinese & [19] \\
\hline & $\begin{array}{l}\mathrm{rs} 1260326 \\
\mathrm{C}>\mathrm{T}\end{array}$ & $N$ & & $538 / 538$ & Han Chinese & [12] \\
\hline & $\begin{array}{l}\text { rs } 2293572 \\
C>G\end{array}$ & $\mathrm{~N}$ & & $538 / 538$ & Han Chinese & [12] \\
\hline & $\begin{array}{l}r s 3817588 \\
A>G\end{array}$ & Y & 1.24 & $1118 / 1161$ & Han Chinese & [22] \\
\hline \multirow[t]{2}{*}{ OCT3 } & rs3088442 G > A & Y & 0.02 & $150 / 152$ & Iran & [23] \\
\hline & rs2292334 G > A & Y & 2.76 & $150 / 152$ & Iran & [23] \\
\hline
\end{tabular}

(by $520 \mathrm{~kJ} /$ day) [15]. SNP rs1276891 and chr7:44,184,184 $3^{\prime} \mathrm{UTR}$ in GCK were associated with T2DM in American Indian [15]. A case-control study in Netherlands revealed weak evidence for an association between rs1799884 and T2DM [16]. In French, GCK rs1799884 was found to increase risk of T2DM [17]. A meta-analysis involved of 24 studies also reported that rs1799884 was associated with the susceptibility of T2DM and the regulation of impaired glucose. Further, this meta-analysis found significant increase of fasting plasma glucose level in rs1799884 A allele compared with G allele [33]. Another study in Moroccans shown significant association of
GCK rs1799884 polymorphism with T2DM [18]. In Japanese, GCK rs4607517 was deemed to be associated with HbA1c level, but not associated with the susceptibility of T2DM [34].

\section{Glucokinase regulator (GCKR) gene}

$G C K R$, also known as GKRP, encodes a protein belonging to the GCKR subfamily of the Sugar Isomerase family of proteins. The GCKR is mainly expressed in liver. is a regulatory protein that inhibits glycolysis, glycogen deposition, and de novo lipogenesis by binding to the glucokinase and impairing it [35]. The mutation or gene variants 
of GCKR was reported to be associated with several clinical manifestation, such as T2DM [36], nonalcoholic fatty liver disease (NAFLD) [37], familial combined hyperlipidemia (FCHL) [38], coronary artery disease, ischemic stroke [39], gout [40] and chronic kidney disease [41]. A number of studies have shown the significant association of GCKR polymorphism with T2DM in different ethnic groups. In Han Chinese population, GCKR rs780094 A allele was reported to be associated with decrease risk of T2DM and obesity. Gene-gene interaction was found to influence fasting glucose between GCKR rs780094 and GCK rs1799884. The influence of GCKR rs1260326 polymorphism on T2DM was also verified in this study [19]. The same results that rs780094 associated with T2DM in Chinese population was also reported by $\mathrm{Li}$ et al. [12] and Gao et al. [22]. In Japanese, the results of multiple regression analysis shown that rs780094 was a marker of T2DM susceptibility [21]. In contrast, some studies have also shown no association between GCKR rs780094 and T2DM [20]. Apart from T2DM, polymorphisms of GCKR was also a susceptibility gene of gestational diabetes. Some studies reported that GCKR rs780094 was associated with the susceptibility of gestational diabetes in Malaysian population [42] and Brazilian [43].

\section{Organic cation transporter 3 (OCT3) gene}

OCT3, also known as $S L C 22 A 3$, located at 6q 25.3 on human chromosome with 15 exons. OCT3 is a polyspecific organic cation transporter mainly expressed in the liver, kidney and intestine. OCT3 is contributed to transfer many endogenous small molecules, drugs and environmental toxins [44]. Therefore, mutations and variants in OCT3 will influence the development of various disease and the efficacy of multiple drugs. SNPs in OCT3 have been shown to be related to diverse conditions, including lipoprotein(a) concentration, cardiovascular disease [44], colorectal cancer [45], metformin pharmacokinetics, esophageal cancer [46], pancreatic cancer [47], and T2DM [23]. In Iranian, OCT3 rs3088442 $\mathrm{G}>\mathrm{A}$ was reported to be a protective factor of T2DM, while rs2292334 to be a risk factor of T2DM [23]. As a drug transporter, there were more studies reported the relationship between polymorphisms of OCT3 and metformin. Wang et al. hold the view that the absolute bioavailability of metformin in oct $3+/+$ mice was significantly increased compared with the oct3-/- mice [48]. Another study reported that OCT3 played an important role in the absorption and elimination of metformin in mice [49]. In Korea, OCT3 haplotype was reported to influence the pharmacokinetics of metformin [50]. And OCT3 was responsible for metformin accumulation and secretion in salivary glands [51]. In T2DM patients, the mean reduction in HbA1c levels was higher in patients with OCT3 rs2292334 A allele than in those with the homozygous $\mathrm{G}$ allele [52]. In Pakistani population, the A allele of OCT3 rs3088442 was a protective factor and associated with clinical efficacy of metformin [53].

\section{Conclusions}

With the development of living standard, the incidence of diabetes is increasing rapidly around the world. This urges us to identify the high-risk individuals at an early stage so as to prevent or put off the development of diabetes. As we all known, diabetes is a disease resulted from many factors and their interactions, including environment, eating habits, lifestyle, ethnicity, and family history. Apart from these, genetic factors also play an important role in the occurrence of diabetes. And genetic factors also interact with environment to induce the individuals to diabetes. This is the reason why a susceptibility gene might show different phenotype in different populations or regions. Various studies have reported the association between genetic variants and the susceptibility of T2DM. In this manuscript, we summarized the results on the association of G6PC2, GCK, GCKR and OCT3 genes with T2DM from various global studies. And hope this review could possibly give a better perspective to help researchers understanding the pathogenesis of T2DM. Results verify the polymorphisms of $G C K$ and $O C T 3$ genes have potential effect on T2DM whereas the relationship between G6PC2, GCKR and T2DM susceptibility is controversial in different studies. The difference in ethnicity and environment may account for this discrepancy. Nevertheless, further research that investigate their role in T2DM is required in more and larger groups globally. Only in this way we can understand the biological and molecular mechanism of T2DM thoroughly, and we can find out more precise biomarker to identify at-risk patients in early stage.

\section{Acknowledgements \\ This research did not receive any specific grant from funding agencies in the public, commercial or not-for-profit sectors.}

\section{Authors' contributions}

$\mathrm{CL}$ conceived the review, $C L$ and $Y Y$ wrote the most of text, $X L$ wrote the introduction part, ZL and HL modified the text and QT checked. All authors read and approved the final manuscript.

Funding

Not applicable.

Availability of data and materials

Not applicable.

Ethics approval and consent to participate

Not applicable.

Consent for publication

Not applicable. 


\section{Competing interests}

The authors declare that they have no competing interests.

\section{Author details}

${ }^{1}$ Department of Pharmacy, The Affiliated Zhuzhou Hospital Xiangya Medical College CSU, Zhuzhou 412007, Hunan, China. ${ }^{2}$ Laboratory Medical Center, The Affiliated Zhuzhou Hospital Xiangya Medical College CSU, Zhuzhou 412007. China. ${ }^{3}$ Department of Metabolism and Endocrinology, The Affiliated Zhuzhou Hospital Xiangya Medical College CSU, Zhuzhou 412007, China.

Received: 29 June 2020 Revised: 22 October 2020 Accepted: 26 October 2020

Published online: 04 November 2020

\section{References}

1. Cho NH, Shaw JE, Karuranga S, et al. IDF Diabetes Atlas: Global estimates of diabetes prevalence for 2017 and projections for 2045. Diabetes Res Clin Pract. 2018:138:271-81.

2. $X u Y$, Wang $L, H e J$, et al. Prevalence and control of diabetes in Chinese adults. JAMA. 2013;310(9):948-59.

3. Zimmet PZ, Magliano DJ, Herman WH, Shaw JE. Diabetes: a 21st century challenge. Lancet Diabetes Endocrinol. 2014;2(1):56-64.

4. Zhang Y, Pan XF, Chen J, et al. Combined lifestyle factors and risk of incident type 2 diabetes and prognosis among individuals with type 2 diabetes: a systematic review and meta-analysis of prospective cohort studies. Diabetologia 2019.

5. Kwak SH, Park KS. Recent progress in genetic and epigenetic research on type 2 diabetes. Exp Mol Med. 2016;48:e220.

6. Li Q, Li C, Li H, et al. Effect of AMP-activated protein kinase subunit alpha 2 (PRKAA2) genetic polymorphisms on susceptibility to type 2 diabetes mellitus and diabetic nephropathy in a Chinese population. J Diabetes. 2018;10(1):43-9.

7. Hasan MM, Hosen MB, Rahman MM, Howlader M, Kabir Y. Association of ATP binding cassette transporter 1 (ABCA 1) gene polymorphism with type 2 diabetes mellitus (T2DM) in Bangladeshi population. Gene. 2019;688:151-4

8. Lin Z, Wang Y, Zhang B, Jin Z. Association of type 2 diabetes susceptible genes GCKR, SLC30A8, and FTO polymorphisms with gestational diabetes mellitus risk: a meta-analysis. Endocrine. 2018;62(1):34-45.

9. Brayner B, Kaur G, Keske MA, Livingstone KM. FADS polymorphism, omega-3 fatty acids and diabetes risk: a systematic review. Nutrients. 2018:10(6):758.

10. Zhou KC, Liu HW, Wang C, Fu YJ, Jin F. Association of transcription factor 7-like 2 (TCF7L2) gene polymorphism with type 2 diabetes mellitus in Chinese Korean ethnicity population. Med (Baltim). 2019;98(5):e14288.

11. Papazafiropoulou AK, Papanas N, Melidonis A, Maltezos E. Family history of type 2 diabetes: does having a diabetic parent increase the risk? Curr Diabetes Rev. 2017;13(1):19-25.

12. Zhou W, Li Y, Zhang L, et al. Gene-gene interactions lead to higher risk for development of type 2 diabetes in a Chinese Han population: a prospective nested case-control study. Lipids Health Dis. 2018;17(1):179.

13. Hu C, Zhang R, Wang C, et al. A genetic variant of G6PC2 is associated with type 2 diabetes and fasting plasma glucose level in the Chinese population. Diabetologia. 2009;52(3):451-6.

14. Al-Daghri NM, Pontremoli C, Cagliani R, et al. Susceptibility to type 2 diabetes may be modulated by haplotypes in G6PC2, a target of positive selection. BMC Evol Biol. 2017:17(1):43.

15. Muller $Y L$, Piaggi $P$, Hoffman $D$, et al. Common genetic variation in the glucokinase gene (GCK) is associated with type 2 diabetes and rates of carbohydrate oxidation and energy expenditure. Diabetologia. 2014;57(7):1382-90

16. Reiling E, van Groenewoud TRE, et al. Combined effects of single-nucleotide polymorphisms in GCK, GCKR, G6PC2 and MTNR1B on fasting plasma glucose and type 2 diabetes risk. Diabetologia. 2009;52(9):1866-70.

17. Cauchi S, Nead KT, Choquet $H$, et al. The genetic susceptibility to type 2 diabetes may be modulated by obesity status: implications for association studies. BMC Med Genet. 2008;9:45.
18. Cauchi S, Ezzidi I, El AY, et al. European genetic variants associated with type 2 diabetes in North African Arabs. Diabetes Metab. 2012:38(4):316-23.

19. Qi Q, Wu Y, Li H, et al. Association of GCKR rs780094, alone or in combination with GCK rs1799884, with type 2 diabetes and related traits in a Han Chinese population. Diabetologia. 2009;52(5):834-43.

20. Gao K, Wang J, Li L, et al. Polymorphisms in four genes (KCNQ1 rs151290, KLF14 rs972283, GCKR rs780094 and MTNR1B rs10830963) and their correlation with type 2 diabetes mellitus in Han Chinese in Henan Province, China. Int J Environ Res Public Health. 2016;13(3):260.

21. Onuma H, Tabara Y, Kawamoto R, et al. The GCKR rs780094 polymorphism is associated with susceptibility of type 2 diabetes, reduced fasting plasma glucose levels, increased triglycerides levels and lower HOMA-IR in Japanese population. J Hum Genet. 2010:55(9):600-4.

22. Ling Y, Li X, Gu Q, et al. Associations of common polymorphisms in GCKR with type 2 diabetes and related traits in a Han Chinese population: a case-control study. BMC MED GENET. 2011;12:66

23. Mahrooz A, Alizadeh A, Hashemi-Soteh MB, Ghaffari-Cherati M, Hosseyni-Talei SR. Polymorphic Variants rs3088442 and rs2292334 in the Organic Cation Transporter 3 (OCT3) Gene and Susceptibility Against Type 2 Diabetes: Role of their Interaction. ARCH MED RES. 2017:48(2):162-8.

24. Bosma KJ, Rahim M, Singh K, et al. Pancreatic islet beta cell-specific deletion of G6pc2 reduces fasting blood glucose. J Mol Endocrinol. 2020:64(4):235-48

25. Boortz KA, Syring KE, Dai C, et al. G6PC2 modulates fasting blood glucose in male mice in response to stress. Endocrinology. 2016;157(8):3002-8.

26. Bouatia-Naji N, Rocheleau G, Van Lommel L, et al. A polymorphism within the G6PC2 gene is associated with fasting plasma glucose levels. Science. 2008:320(5879):1085-8.

27. Baerenwald DA, Bonnefond A, Bouatia-Naji N, et al. Multiple functional polymorphisms in the G6PC2 gene contribute to the association with higher fasting plasma glucose levels. Diabetologia. 2013;56(6):1306-16.

28. Wessel J, Chu AY, Willems SM, et al. Low-frequency and rare exome chip variants associate with fasting glucose and type 2 diabetes susceptibility. Nat Commun. 2015;6:5897.

29. Shi Y, Li Y, Wang J, et al. Meta-analyses of the association of G6PC2 allele variants with elevated fasting glucose and type 2 diabetes. PLOS ONE. 2017:12(7):e181232.

30. Osbak KK, Colclough K, Saint-Martin C, et al. Update on mutations in glucokinase (GCK), which cause maturity-onset diabetes of the young, permanent neonatal diabetes, and hyperinsulinemic hypoglycemia. Hum Mutat. 2009;30(11):1512-26.

31. Liu L, Liu Y, Ge X, et al. Insights into pathogenesis of five novel GCK mutations identified in Chinese MODY patients. Metabolism. 2018:89:8-17.

32. Khan IA, Jahan P, Hasan $Q$ Rao P. Genetic confirmation of T2DM metaanalysis variants studied in gestational diabetes mellitus in an Indian population. Diabetes Metab Syndr. 2019:13(1):688-94.

33. Fu D, Cong X, Ma Y, et al. Genetic polymorphism of glucokinase on the risk of type 2 diabetes and impaired glucose regulation: evidence based on 298,468 su bjects. PLoS ONE. 2013;8(2):e55727.

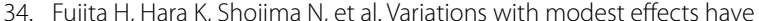
an important role in the genetic background of type 2 diabetes and diabetes-related traits. J Hum Genet. 2012;57(12):776-9.

35. Brouwers M, Jacobs C, Bast A, Stehouwer C, Schaper NC. Modulation of glucokinase regulatory protein: a double-edged sword? Trends Mol Med. 2015:21(10):583-94.

36. Dupuis J, Langenberg C, Prokopenko I, et al. New genetic loci implicated in fasting glucose homeostasis and their impact on type 2 diabetes risk. Nat Genet. 2010;42(2):105-16

37. Nobili V, Alisi A, Valenti L, et al. NAFLD in children: new genes, new diagnostic modalities and new drugs. Nat Rev Gastroenterol Hepatol. 2019:16(9):517-30.

38. De Castro-Oros I, Cenarro A, Tejedor MT, et al. Common genetic variants contribute to primary hypertriglyceridemia without differences between familial combined hyperlipidemia and isolated hypertriglyceridemia. Circ Cardiovasc Genet. 2014;7(6):814-21.

39. Zhou YJ, Hong SC, Yin RX, et al. Polymorphisms in the GCKR are associated with serum lipid traits, the risk of coronary artery disease and ischemic stroke. Int J Clin Exp Med. 2015;8(7):10678-86. 
40. Matsuo $\mathrm{H}$, Yamamoto $\mathrm{K}$, Nakaoka $\mathrm{H}$, et al Genome-wide association study of clinically defined gout identifies multiple risk loci and its association with clinical subtypes. Ann Rheum Dis. 2016;75(4):652-9.

41. Hishida A, Takashima N, Turin TC, et al. GCK, GCKR polymorphisms and risk of chronic kidney disease in Japanese individuals: data from the J-MICC Study. J Nephrol. 2014;27(2):143-9.

42. Jamalpour S, Zain SM, Mosavat M, Mohamed Z, Omar SZ. A case-control study and meta-analysis confirm glucokinase regulatory gene rs780094 is a risk factor for gestational diabetes mellitus. Gene. 2018:650:34-40.

43. Anghebem-Oliveira MI, Webber S, Alberton D, et al. The GCKR gene polymorphism rs780094 is a risk factor for gestational diabetes in a Brazilian population. J Clin Lab Anal. 2017;31(2):e22035.

44. Paquette $M$, Bernard S, Baass A. SLC22A3 is associated with lipoprotein (a) concentration and cardiovascular disease in familial hypercholesterolemia. Clin Biochem. 2019;66:44-8.

45. Ren A, Sun S, Li S, et al. Genetic variants in SLC22A3 contribute to the susceptibility to colorectal cancer. Int J Cancer. 2019;145(1):154-63.

46. Xiong JX, Wang YS, Sheng J, et al. Epigenetic alterations of a novel antioxidant gene SLC22A3 predispose susceptible individuals to increased risk of esophageal cancer. Int J Biol Sci. 2018;14(12):1658-68.

47. Mohelnikova-Duchonova B, Strouhal O, Hughes DJ, et al. SLC22A3 polymorphisms do not modify pancreatic cancer risk, but may influence overall patient survival. Sci Rep. 2017;7:43812.

48. Shirasaka Y, Lee N, Zha W, Wagner D, Wang J. Involvement of organic cation transporter 3 (Oct3/SIc22a3) in the bioavailability and pharmacokinetics of antidiabetic metformin in mice. Drug Metab Pharmacokinet. 2016;31(5):385-8.

49. Chen EC, Liang X, Yee SW, et al. Targeted disruption of organic cation transporter 3 attenuates the pharmacologic response to metformin. MOL PHARMACOL. 2015;88(1):75-83.

50. Kwon EY, Chung JY, Park HJ, et al. OCT3 promoter haplotype is associated with metformin pharmacokinetics in Koreans. Sci Rep. 2018;8(1):16965.

51. Lee N, Duan H, Hebert MF, et al. Taste of a pill: organic cation transporter-3 (OCT3) mediates metformin accumulation and secretion in salivary glands. J Biol Chem. 2014;289(39):27055-64.

52. Hosseyni-Talei SR, Mahrooz A, Hashemi-Soteh MB, Ghaffari-Cherati M, Alizadeh A. Association between the synonymous variant organic cation transporter 3 (OCT3)-1233G >A and the glycemic response following metformin therapy in patients with type 2 diabetes. Iran J Basic Med Sci. 2017;20(3):250-5.

53. Moeez S, Riaz S, Masood N, et al. Evaluation of the rs3088442 G>A SLC22A3 gene polymorphism and the role of microRNA 147 in groups of adult Pakistani populations with type 2 diabetes in response to metformin. Can J Diabetes. 2019;43(2):128-35.

\section{Publisher's Note}

Springer Nature remains neutral with regard to jurisdictional claims in published maps and institutional affiliations.
Ready to submit your research? Choose BMC and benefit from:

- fast, convenient online submission

- thorough peer review by experienced researchers in your field

- rapid publication on acceptance

- support for research data, including large and complex data types

- gold Open Access which fosters wider collaboration and increased citations

- maximum visibility for your research: over $100 \mathrm{M}$ website views per year

At BMC, research is always in progress.

Learn more biomedcentral.com/submissions 